\title{
Characterization of Polymorphs of a Novel Quinolinone Derivative, TA-270 (4-Hydroxy-1-methyl-3-octyloxy-7-sinapinoylamino-2(1H)- quinolinone)
}

\author{
Nobuyuki Kimura, ${ }^{a}$ Hiroyuki FukuI,${ }^{a}$ Hidetsugu Takagaki, ${ }^{a}$ Etsuo Yonemochi, ${ }^{b}$ and \\ Katsuhide TERADA ${ }^{*, b}$ \\ Central Research Laboratories, Dainippon Ink and Chemicals, Inc., ${ }^{a} 631$ Sakado, Sakura, Chiba 285-8668, Japan and \\ School of Pharmaceutical Sciences, Toho University, 2-2-1 Miyama, Funabashi, Chiba 274-8510, Japan. \\ Received May 25, 2001; accepted June 30, 2001
}

\begin{abstract}
The polymorphic forms and amorphous form of TA-270 (4-hydroxy-1-methyl-3-octyloxy-7-sinapinoylamino2(1H)-quinolinone), a newly developed antiallergenic compound, were characterized by powder X-ray diffractometry, thermal analysis, infrared spectroscopy and solid state ${ }^{13} \mathrm{C}-\mathrm{NMR}$. The intrinsic dissolution rates of polymorphic forms were measured using the rotating disk method at $37^{\circ} \mathrm{C}$. The dissolution rates correlated well with the thermodynamic stability of each polymorphic form. These dissolution properties were clearly reflected in the oral bioavailability of TA-270 in rats. The transition behavior for each polymorph and for the amorphous form was studied under the high temperature and humidity conditions. The $\boldsymbol{\beta}$ - and $\boldsymbol{\delta}$-forms were transformed into the $\alpha$-form by heating. The amorphous form was also easily crystallized into $\alpha$-form by heating, however it was relatively stable under humidified conditions. The internal molecular packing of each polymorph was estimated from IR and solid state NMR spectral analysis.
\end{abstract}

Key words polymorph; amorphous; transformation; bioavailability; infrared spectroscopy; solid state NMR

TA-270 (4-hydroxy-1-methyl-3-octyloxy-7-sinapinoylamino$2(1 H)$-quinolinone, Fig. 1) is a newly developed antiallergy compound. TA-270 inhibits the immediate- and late-airway responses, pulmonary inflammatory cell accumulation, and airway hypersensitiveness. ${ }^{1)}$ There are several useful reviews on the pharmaceutical applications of polymorphs, ${ }^{2-6)}$ and the study of polymorphism of newly developed compounds is important. A polymorphism is a solid material with at least two different molecular arrangements giving distinct crystal species. There can be large differences in their physical properties and also differences in bioavailability. ${ }^{7,8)}$ Several techniques for solid state measurements have been reported in the study of polymorphs: microscopy, infrared (IR) spectroscopy, ${ }^{9}$ differential scanning calorimetry (DSC), ${ }^{10-12)}$ powder X-ray diffractometry, ${ }^{13,14)}$ and solid state NMR spectroscopy. ${ }^{15-21)}$

In the present study, the characterization of various crystalline forms of TA-270 was examined as a preformulation study. To confirm the molecular state of the polymorphic forms, powder X-ray diffractometry, thermal analysis, IR spectroscopy and solid state ${ }^{13} \mathrm{C}-\mathrm{NMR}$ spectroscopy were performed. The intrinsic dissolution rate of each form was analyzed based on the rotating disk method. In vivo studies were also performed using Male Cr:CD strain rats.

\section{Experimental}

Materials TA-270 was synthesized by the synthetic department of Dainippon Ink and Chemicals, Inc. and the purity of the compound was above $99 \%$. The $\alpha, \beta$ and $\delta$ polymorphic forms were prepared by recrystallization from acetonitrile, ethanol, and acetone, respectively. The amorphous form was prepared by milling the $\beta$-form with a vibrating mill (CMT MGF, TI-300). All other chemicals and solvents were of analytical reagent grade.

Powder X-Ray Diffraction The powder X-ray diffraction pattern was measured with an X-ray diffractometer (Model RINT Ultima, Rigaku Denki). The conditions of measurement were as follows: target $\mathrm{Cu}$, monochrometer graphite, voltage $40 \mathrm{kV}$ and current $30 \mathrm{~mA}$, with a scanning speed of $2 \% \mathrm{~min}$.

Thermal Analysis DSC thermograms were obtained by a differential scanning calorimeter (Model DSC7, Perkin-Elmer). The measurements were made using an aluminum sample pan (sample weights were 6-10 mg) under a nitrogen atmosphere at a scanning speed of 5 or $20^{\circ} \mathrm{C} / \mathrm{min}$. Temperature scale was calibrated by an Indium standard.

Thermogravimetry (TG) curves were obtained with a thermogravimeter (Model TGA7, Perkin-Elmer).

IR Spectroscopy IR spectra were obtained with a Fourier transform (FT)-IR spectrometer (Perkin Elmer Spectrum One) using a diffuse reflectance technique. ${ }^{22}$

Dissolution Rate Measurement The intrinsic dissolution rate was determined according to the rotating disk method under the following conditions: $2 \% \mathrm{w} / \mathrm{v}$ Tween $80-\mathrm{pH} 8.0$ phosphate buffer $\left(37^{\circ} \mathrm{C}\right)$, stirring rate of $100 \mathrm{rpm}$. A disk (diameter: $8 \mathrm{~mm}$ ) was prepared by compressing a $100 \mathrm{mg}$ sample under a pressure of $196 \mathrm{MPa}$ in a hydraulic press. It was confirmed by powder X-ray diffraction measurement that no polymorphic transition took place during the compression. The concentration of dissolved drug was measured at $352 \mathrm{~nm}$ with an UV spectrophotometer (JASCO V-550). Each point on the profile represents the average of three determinations.

In Vivo Studies Animals: Male Cr:CD strain rats at 6 weeks old were obtained from Charles River Japan Inc. Male rats ( 7 weeks old) were fasted overnight prior to experiments. The oral use samples were prepared as an aqueous suspension with $0.5 \%$ methylcellulose and administered by a gastric intubation at a dose of $100 \mathrm{mg} / \mathrm{kg} / 5 \mathrm{ml}$. The plasma concentration of TA270 was measured with a high performance liquid chromatography (HPLC) (JASCO GULLIVER). Each point on the profile represents the average of three determinations.

HPLC: HPLC was used to determine the content of TA-270. The HPLC equipment was as follows: an octadecyl silica (ODS) column (Inertsil ODS2, $150 \times 4.6 \mathrm{~mm}$ i.d., GL Sciences), UV-VIS detector (UV-970; JASCO). Gradient elution was performed from ethanol $/ 20 \mathrm{mmol}$ phosphate buffer $(1 / 1$, mobile phase A) to ethanol/20 $\mathrm{mmol}$ phosphate buffer $(9 / 1$, mobile phase B) over $30 \mathrm{~min}$, the flow rate was $1.0 \mathrm{ml} / \mathrm{min}$. Absorbance was detected at $340 \mathrm{~nm}$.

Solid State ${ }^{13} \mathrm{C}$-NMR Solid state ${ }^{13} \mathrm{C}-\mathrm{NMR}$ was performed on a spectrometer (JEOL GSX-400) with a $8 \mathrm{~mm}$ (diameter) cross polarization magic angle spinning (CP/MAS) probe and hexamethylbenzene as an external reference.

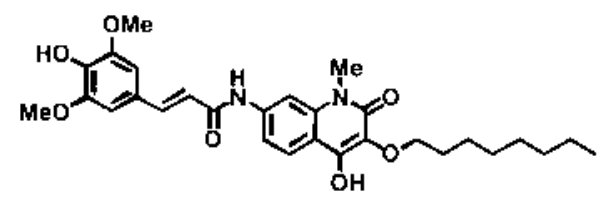

Fig. 1. Structure of TA-270 


\section{Results and discussion}

Characterization of the Three Polymorphs and Amorphous Form The powder X-ray diffraction patterns of different crystal preparations are shown in Fig. 2. $\alpha$-Form gave diffraction peaks at $2 \theta=7.1^{\circ}, 10.1^{\circ}, 22.8^{\circ}$, and $\beta$-form showed peaks at $2 \theta=7.6^{\circ}, 8.8^{\circ}, 17.8^{\circ}, 22.8^{\circ}$. The characteristic diffraction peaks of the $\delta$-form were observed at $2 \theta=$ $5.7^{\circ}, 11.6^{\circ}, 13.2^{\circ}, 16.0^{\circ}, 20.4^{\circ}, 23.9^{\circ}, 26.6^{\circ}$. The powder Xray diffraction patterns of each crystal form showed different patterns which confirmed the presence of the three different crystal structures of TA-270. On the other hand, ground TA270 gave no distinctive diffraction, which was clearly different from those of the $\alpha-, \beta$-, $\delta$-forms. These polymorphs and amorphous of TA-270 were further characterized by other physical methods.

Figure 3 shows the DSC thermograms of the three polymorphs and amorphous form measured at a scanning speed of $5^{\circ} \mathrm{C} / \mathrm{min}$. The DSC thermograms of the $\alpha$ - and $\delta$-forms showed a sharp endothermic peak due to melting at $186^{\circ} \mathrm{C}$ and $118^{\circ} \mathrm{C}$, respectively. The DSC thermograms of the $\beta$ form showed a broad endothermic peak at $144^{\circ} \mathrm{C}$. The reason why a broad melting peak appeared for the $\beta$-form is discussed in section 3.4 (internal structure of polymorphs). In the DSC thermograms of the amorphous form, there were no endothermic or exothermic peaks at a scanning speed of $20^{\circ} \mathrm{C} / \mathrm{min}$. However, an endothermic peak was observed at a scanning speed of $5{ }^{\circ} \mathrm{C} / \mathrm{min}$, due to the crystallization of the amorphous form during slow heating. The TG curve of each form showed no weight loss until melting. To determine the level of impurities, elemental analysis and HPLC was performed. The content of $\alpha-, \beta-, \delta$ - and amorphous forms determined by HPLC were $99.2 \%, 99.5 \%, 99.1 \%$ and $99.4 \%$, respectively. The values obtained by elemental analysis were coincident with the theoretical values, as shown in Table 1 . These results suggested that the three preparations did not contain solvents of crystallization or impurities. Therefore, we confirmed that the three crystal forms of TA270 were different polymorphs ( $\alpha$-, $\beta$ - and $\delta$ - forms).

Transition Behavior of Polymorphs As shown in Fig.

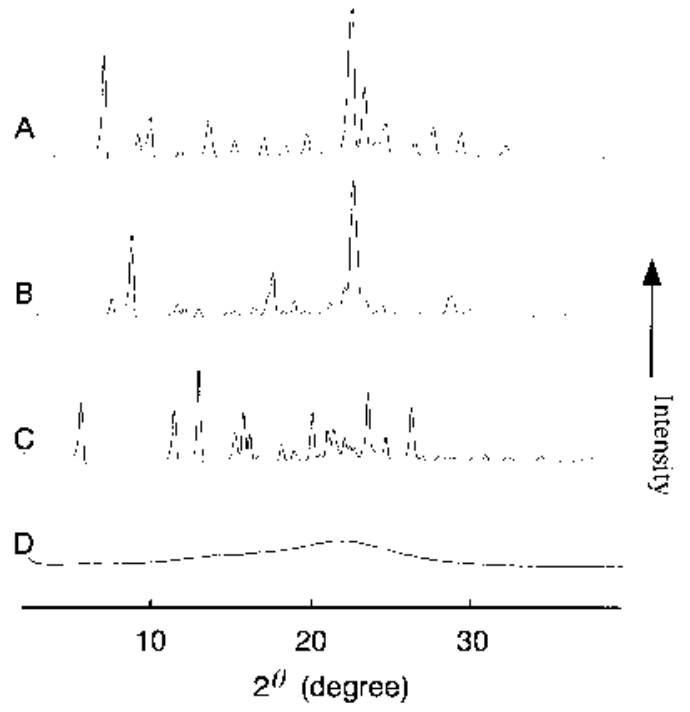

Fig. 2. Powder X-Ray Diffraction Patterns of Polymorphic Forms of TA270

A, $\alpha$-form; B, $\beta$-form; C, $\delta$-form; D, amorphous form.
3 , the melting temperature and heat of fusion of the $\alpha$-form were $186{ }^{\circ} \mathrm{C}$ and $433 \mathrm{~kJ} / \mathrm{mol}$, respectively. On the other hand, the corresponding data for the $\beta$ - and $\delta$-forms were smaller than for the $\alpha$-form. The $\beta$ - and $\delta$-forms showed exothermic peaks at around $170^{\circ} \mathrm{C}$, followed by an endothermic peak at $186^{\circ} \mathrm{C}$, due to fusion of the $\alpha$-form. The amorphous form also showed an exothermic peak at around $170^{\circ} \mathrm{C}$ and endothermic peaks at $186^{\circ} \mathrm{C}$. The powder X-ray diffraction pattern of an amorphous sample heated at $170^{\circ} \mathrm{C}$ was identical to that of the $\alpha$-form, indicating that the peak of $170^{\circ} \mathrm{C}$ was due to crystallization of the amorphous form. These results indicated that the $\alpha$-form is the thermodynamically stable form of TA270, and the $\beta$-, $\delta$-, and amorphous forms are transformed to $\alpha$-form by thermal treatment.

The isothermal transition behavior of the amorphous form was investigated since it is a metastable state and might be crystallized during storage under ambient conditions. Powder $\mathrm{X}$-ray diffraction measurements of the amorphous form were conducted after storage at $40{ }^{\circ} \mathrm{C}$ and $80 \%$ relative humidity (RH) for $14 \mathrm{~d}$, and no diffraction peak due to crystals was observed.

Dissolution Rates and Absorption Behaviors of the Three Polymorphs and the Amorphous Form The intrinsic dissolution rates were determined for the three crystal forms and the amorphous form of TA- 270 at $37^{\circ} \mathrm{C}$. The samples in the dissolution medium were taken out, dried, and subjected to powder X-ray diffraction measurements to gain insight into phase changes during the dissolution. Changes in the crystal forms of TA-270 were not observed in this experi-

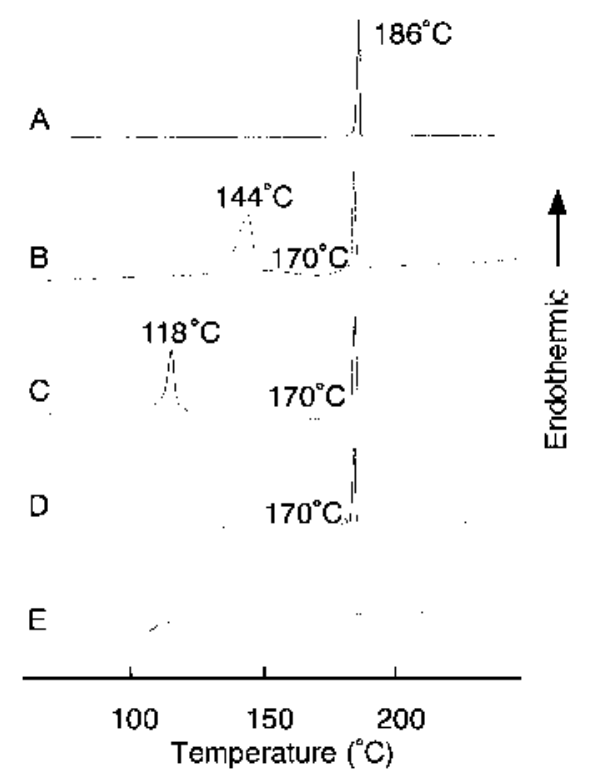

Fig. 3. DSC Thermograms of Polymorphic Forms of TA-270

$\mathrm{A}, \alpha$-form; B, $\beta$-form; C, $\delta$-form; D, E, amorphous form. The measurements were made at a scanning speed of $5^{\circ} \mathrm{C} / \mathrm{min}(\mathrm{A}-\mathrm{D})$ and $20^{\circ} \mathrm{C} / \mathrm{min}(\mathrm{E})$.

Table 1. Elemental Analysis of Polymorphic Forms of TA-270 $\left(\mathrm{C}_{29} \mathrm{H}_{36} \mathrm{~N}_{2} \mathrm{O}_{7}\right)$

\begin{tabular}{llll}
\hline \hline & $\mathrm{C}(\%)$ & $\mathrm{H}(\%)$ & $\mathrm{N}(\%)$ \\
\hline Calcd & 66.4 & 6.9 & 5.3 \\
$\alpha$-Form & 66.3 & 6.8 & 5.2 \\
$\beta$-Form & 66.3 & 6.8 & 5.2 \\
$\delta$-Form & 66.1 & 7.0 & 5.1 \\
\hline
\end{tabular}




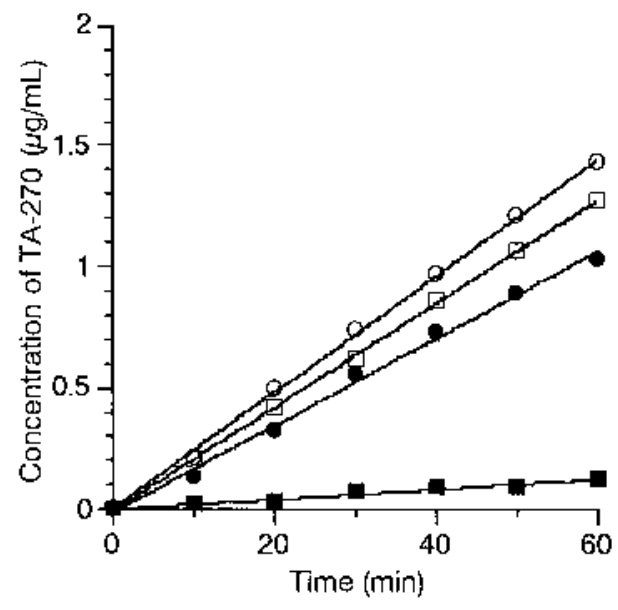

Fig. 4. Dissolution Profiles of Polymorphic Forms of TA-270 in 2\%w/v Tween80-pH 8.0 Phosphate Buffer at $37^{\circ} \mathrm{C}$

$\mathbf{\square}, \alpha$-form;,$\beta$-form; $\square, \delta$-form; $\bigcirc$, amorphous form.

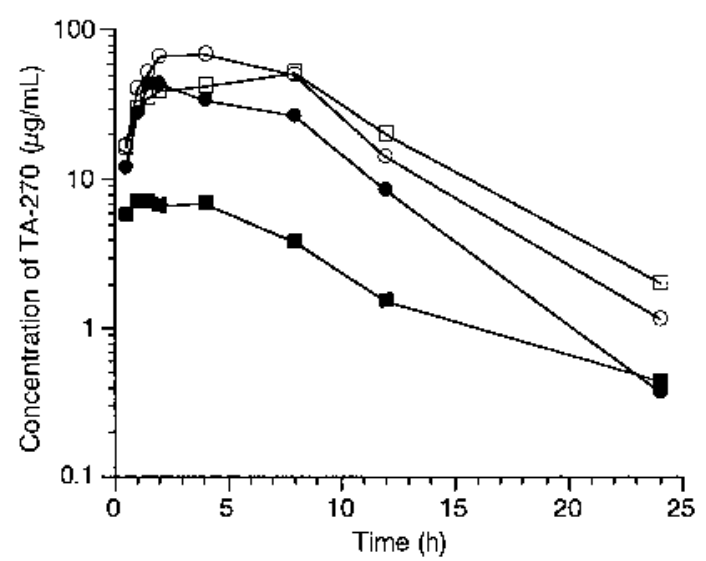

Fig. 5. Plasma Concentrations of TA-270 after Oral Administration of Polymorphic Forms to Rats

$\boldsymbol{\square}, \alpha$-form; $\bullet, \beta$-form; $\square, \delta$-form; $\bigcirc$, amorphous form.

ment. The dissolution profiles measured by the rotating disk method are shown in Fig. 4. The dissolution rate of the amorphous form was greater than that of the crystal forms, whereas dissolution of the $\alpha$-form was significantly slower than that of the others. The difference in crystal forms significantly altered the dissolution rate of TA-270, and the dissolution rate constants of the $\alpha-, \beta$-, $\delta$-, and amorphous forms were calculated as $2.38,15.6,21.1$, and $24.1 \times 10^{-3} \mu \mathrm{g} / \mathrm{ml}$. $\mathrm{min}$, respectively. The solubility of the amorphous form might be higher compared to the three polymorphs.

Figure 5 shows the plasma concentration-time profiles after oral administration of the three crystal forms and the amorphous form of TA-270 in rats. The AUCs (area under the concentration-time curve) of $\alpha-, \beta-, \delta$-, and amorphous forms were calculated as $68,375,598$ and $662 \mu \mathrm{g} \cdot \mathrm{h} / \mathrm{ml}$, respectively. The oral bioavailability of TA-270 increased in the order of $\alpha$-form $\ll \beta$-form $<\delta$-form $<$ amorphous form, and that of the $\delta$ - and amorphous forms were 10 times higher than that of the $\alpha$-form, reflecting the in vitro dissolution behavior of the polymorphs.

Internal Structure of Polymorphs Solid state ${ }^{13} \mathrm{C}-\mathrm{NMR}$ spectroscopic studies were employed to gain insight into the internal structure of the TA-270 polymorphs. Figure 6 shows

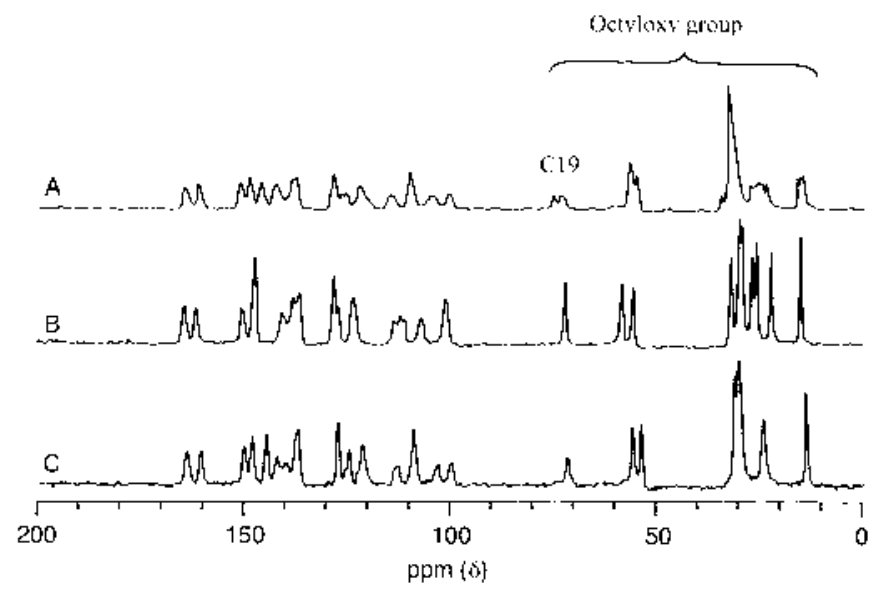

Fig. 6. Solid State ${ }^{13}$ C-NMR Spectra of Polymorphic Forms of TA-270 A, $\alpha$-form; B, $\beta$-form; C, $\delta$-form.

${ }^{13} \mathrm{C}$-NMR spectra for the $\alpha$-, $\beta$-, and $\delta$-forms measured in a $\mathrm{CP}-\mathrm{MAS}$ mode. These ${ }^{13} \mathrm{C}-\mathrm{NMR}$ signals were assigned according to the spectrum of TA-270 in dimethyl sulfoxide (DMSO) solution, as shown in Fig. 7 and Table 2. There were some spectral differences between the three polymorphs, suggesting differences in the molecular conformation and crystal packing of TA270. The chemical shift of C19 of the $\alpha$-form, located at the joint of the octyloxy group, was split into two $(75.6,73.7 \mathrm{ppm})$, on the other hand, the chemical shifts of the corresponding carbon in the $\beta$ - and $\delta$ forms were 72.6 and $72.3 \mathrm{ppm}$, respectively. This suggests that two different conformers are present in the unit cell of the crystalline $\alpha$-form. The NMR spectrum of the $\beta$-form was similar to that of the $\delta$-form except for the chemical shifts due to the octyloxy group, observed at $10-70 \mathrm{ppm}$. The densities of the $\alpha$ - and $\beta$-forms were measured pycnometrically to be 1.27 and $0.97 \mathrm{~g} / \mathrm{cm}^{3}$, respectively. These results indicate that the conformation of TA-270 in the $\beta$-form may be different from the other form, and that the environment around the octyloxy group may differ; that is, there may be some free space that allows the carbon chain to rotate due to looser packing of crystals in the $\beta$-form.

The FT-IR spectroscopic studies supported this conclusion, as shown in Fig. 8. A stretching vibration band for a free amino group at $3501 \mathrm{~cm}^{-1}$ was observed in the $\alpha$-form, however, no free amino absorption was observed in the spectra of the other polymorphs. IR absorption bands of the functional groups involving in the intermolecular hydrogen bonding of TA-270 molecules, such as the hydrogen bonded (around $3140 \mathrm{~cm}^{-1}$ ) and free $\left(3500 \mathrm{~cm}^{-1}\right)$ amino groups, showed significant differences in wavelength between the three polymorphs, suggesting the different molecular packing of TA270. Moreover, the stretching vibration band of methylene (octyloxy) group, which appeared around 2850-2940 $\mathrm{cm}^{-1}$, was considerably different between the polymorphs. In this spectral region, a broad peak was observed for the $\beta$ form, whereas, the $\alpha$ - and $\delta$-forms showed sharp peaks. The broad absorption peak was usually observed for the low crystallinity or amorphous samples, therefore, the octyloxy group of the $\beta$-form could be disordered compared with other polymorphs. The obtained results may confirm the slight imperfection of the $\beta$-form that was observed in the broad melting peak in the DSC thermogram and the broad X-ray diffraction 


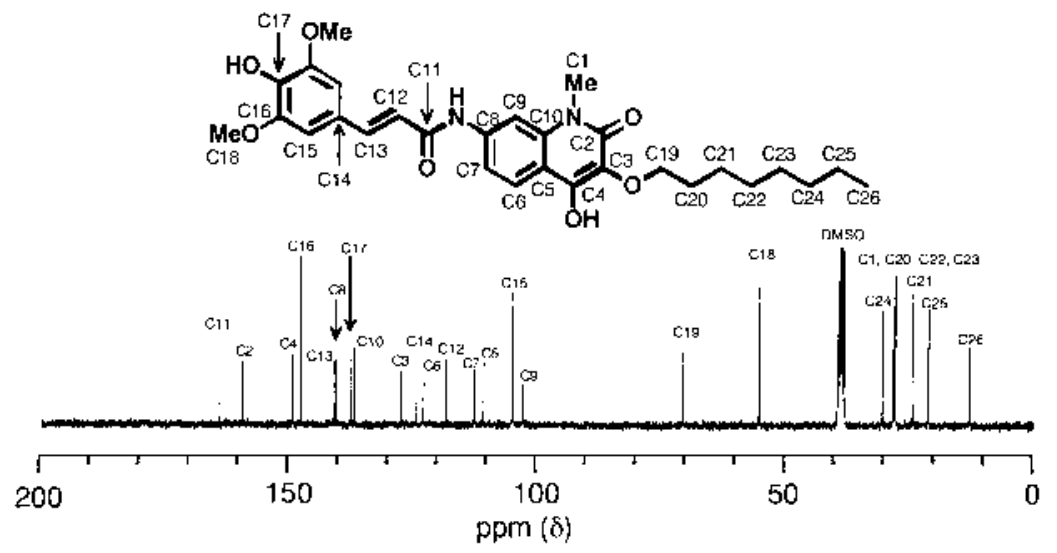

Fig. 7. ${ }^{13} \mathrm{C}-\mathrm{NMR}$ Spectrum of TA-270 in DMSO- $d_{6}$

Table 2. ${ }^{13} \mathrm{C}-\mathrm{NMR}$ Chemical Shifts of TA-270 (in DMSO- $d_{6}$ )

\begin{tabular}{cccccr}
\hline \hline $\begin{array}{c}\text { Chemical } \\
\text { shift } \\
(\delta, \text { ppm })\end{array}$ & Carbon & $\begin{array}{c}\text { Chemical } \\
\text { shift } \\
(\delta, \text { ppm })\end{array}$ & Carbon & $\begin{array}{c}\text { Chemical } \\
\text { shift } \\
(\delta, \text { ppm })\end{array}$ & Carbon \\
\hline 13.86 & $\mathrm{C} 26$ & 71.13 & $\mathrm{C} 19$ & 137.16 & $\mathrm{C} 10$ \\
22.03 & $\mathrm{C} 25$ & 103.43 & $\mathrm{C} 9$ & 137.80 & $\mathrm{C} 17$ \\
25.18 & $\mathrm{C} 21$ & 105.46 & $\mathrm{C} 15$ & 140.85 & $\mathrm{C} 8$ \\
28.61 & $\mathrm{C} 23$ & 111.32 & $\mathrm{C} 5$ & 141.41 & $\mathrm{C} 13$ \\
28.70 & $\mathrm{C} 1$ & 113.18 & $\mathrm{C} 7$ & 148.03 & $\mathrm{C} 16$ \\
28.81 & $\mathrm{C} 22$ & 118.90 & $\mathrm{C} 12$ & 149.67 & $\mathrm{C} 4$ \\
29.11 & $\mathrm{C} 20$ & 123.48 & $\mathrm{C} 6$ & 159.59 & $\mathrm{C} 2$ \\
31.16 & $\mathrm{C} 24$ & 124.86 & $\mathrm{C} 14$ & 164.24 & $\mathrm{C} 11$ \\
55.89 & $\mathrm{C} 18$ & 127.91 & $\mathrm{C} 3$ & & \\
\hline
\end{tabular}

pattern. The observed imperfection of the $\beta$-form did not affect the solubility, because of the good correlation between thermodynamic stability and bioavailability of TA-270 polymorphs.

\section{Conclusions}

In this study, we fully characterized polymorphs of TA270 by various physical methods such as solid state NMR, IR spectroscopy, X-ray powder diffraction measurement and thermal analysis. The intrinsic dissolution rates were in the order of amorphous form $>\delta$-form $>\beta$-form $>\alpha$-form. The dissolution rates were well correlated with the thermodynamic stability of each polymorphic form and also clearly reflected in the oral bioavailability of TA-270 in rats. Transition behavior of each polymorph and the amorphous form was studied under high temperature and high humidity conditions. $\beta$ - and $\delta$-Forms were transformed into the $\alpha$-form by heating. The amorphous form was also easily crystallized into the $\alpha$-form by heating, however, it was relatively stable under humidified conditions. The internal molecular packing of each polymorph was estimated from IR and solid state NMR spectral analysis. The conformational difference of the octyloxy group and the difference in intermolecular hydrogen bonding were assumed to be characteristic for TA-270 polymorphs. The present systematic characterization of TA-270 polymorphs affords a rational basis for the design of solid TA-270 formulations.

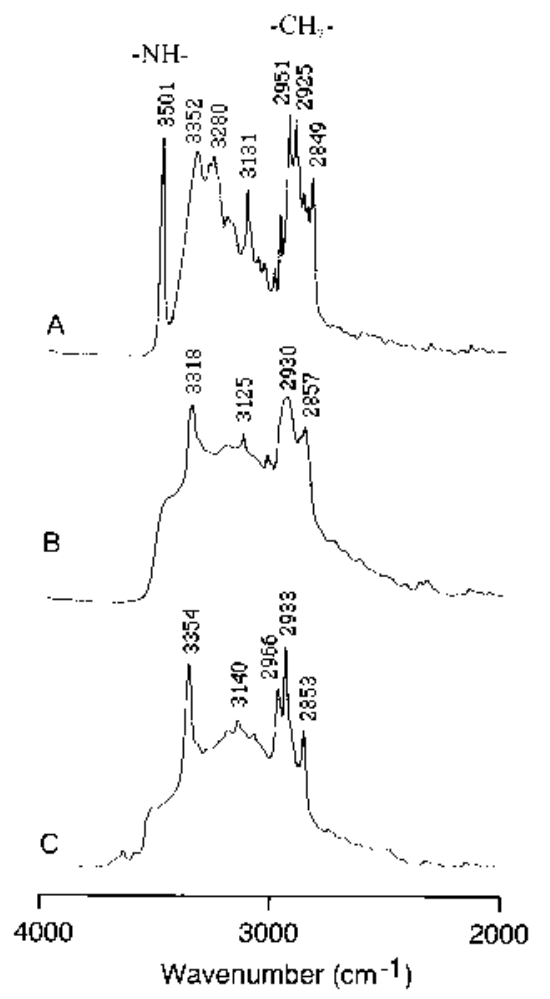

Fig. 8. IR Spectra of Polymorphic Forms of TA-270

A, $\alpha$-form; B, $\beta$-form; C, $\delta$-form

\section{References}

1) Aoki Y., Ishihara M., Koda A., Takagaki H., Eur. J. Pharmacol., 409, $325-330$ (2000).

2) Summers M. P., Carless J. E., Enever R. P., J. Pharm. Pharmacol., 22, 615-616 (1970).

3) Matsuda Y., Kawaguchi S., Kobayashi H., Nishijo J., J. Pharm. Sci., 73, 173-179 (1984).

4) Lin S. Y., J. Pharm. Sci., 81, 572-576 (1992).

5) Uchida T., Yonemochi E., Oguchi T., Terada K., Yamamoto K., Nakai Y., Chem. Pharm. Bull., 41, 1632-1635 (1993).

6) Tros De Ilarduya M. C., Martin C., Goni M. M., Martinez-Oharriz M.C., J. Pharm. Sci., 86, 248-251 (1997).

7) Ledwidge M. T., Draper S. M., Wilcock D. J., Corrigan O. 1., J. Pharm. Sci., 85, 16-21 (1996).

8) Phadnis N. V., Suryanarayanan R. J. Pharm. Sci., 86, 1256-1263 (1997).

9) Lloyd G. R., Craig D. Q. M., Smith A., J. Pharm. Sci., 86, 991—996 (1997). 
10) Yu L., J. Pharm. Sci., 84, 966-974 (1995).

11) Caira M. R., Easter B., Honiball S., Horne A., Nassimbeni L. R., J. Pharm. Sci., 84, 1379-1384 (1995).

12) McMahon L. E., Timmins P., Willlams A. C., York P., J. Pharm. Sci., 85, 1064-1069 (1996).

13) Bugay D. E., Pharm. Res., 10, 317-327 (1993).

14) Li R. C., Mayer P. T., Srived J. S., Fort J. J., J. Pharm. Sci., 85, 773780 (1996).

15) Zhu H., Khankari K., Padden B. E., Munson E. J., Gleason W. B., Grant D. J., W., J. Pharm. Sci., 85, 1026-1033 (1996).

16) Redenti E., Delcanale M., Amari G., Ventura P., Bacchi A., Pelizzi G.,
J. Pharm. Sci., 84, 1126-1133 (1995).

17) Stephenson G. A., Borchardt T. B., Byrn S. R., Bowyer J., Bunnell C. A., Snorex S. V., Yu L., J. Pharm. Sci., 84, 1385-1386 (1995).

18) Stephenson G. A., Stowell J. G., Toma P. H., Pfeiffer R. R., Byrn S. R., J. Pharm. Sci., 86, 1239-1344 (1997).

19) Brittain H. G., J. Pharm. Sci., 86, 405-412 (1997).

20) Duddu S. P., Khln-khin A., Grant D. J. W., Suryanarayanan R., $J$. Pharm. Sci., 86, 340-345 (1997).

21) Ceolin R., Toscani S., Gardette M. F., Agafonov V. N., Dzyabchenko A. V., Bachet B., J. Pharm. Sci., 86, 1062-1065 (1997).

22) Fuller M. P., Griffiths P. R., Anal. Chem., 50, 1906 (1978). 